picture in a case of childhood dermatomyositis. A fiveyear-old girl was first hospitalised in 1971 with muscular pain and weakness accompanied by mild malar erythema and an erythematous/violaceous maculopapular eruption over the extensor surfaces of the interphalangeal joints, elbows, and knees; the electromyogram (EMG) was consistent with myositis. Without treatment the patient presented spontaneous remission during the following months.

In 1975, at 9 years of age, similar symptoms affecting the skin and proximal muscle groups recurred, and a diagnosis of dermatomyositis was confirmed by increase of muscle enzymes (creatine phosphokinase $410 \mathrm{U} / \mathrm{l}$ ) and typical EMG findings. Again the symptomatology disappeared without treatment.

The child led a normal life and played sports. In January 1984 the skin lesions recurred accompanied by periorbital lilac discoloration, cutaneous arteritic lesions on the medial aspect of the thighs, mild proximal muscular weakness, and moderate increase of muscle enzymes. The symptomatology resolved rapidly with a short period of low dose steroids. Generally, childhood dermatomyositis follows a uniphasic course. The activity of the disease may last from only a few months to two or three years followed by recovery; ${ }^{2}$ during this period recurrence of the symptomatology is generally the consequence of premature discontinuation of treatment. On the contrary in our patient, as in the adult reported by Foley and Payne, the clinical course of the disease was polyphasic with recurrences separated by long periods of spontaneous remissions.

Department of Pediatrics

University of Pavia,

ALBERTO MARTINI

Policlinico S. Matteo,

27100 Pavia, Italy

References

1 Foley Jane A, Roland Payne C M E. Unusual case of dermatomyositis. Ann Rheum Dis 1984; 43: 662-3.

2 Ansell Barbara M. Rheumatic disorders in childhood. London: Butterworth, 1980.

\section{The lupus anticoagulant, pulmonary thromboembolism, and fatal pulmonary hypertension}

SIR, The article by Anderson and $\mathrm{Ali}^{1}$ is an important contribution which may provide insights into the development of pulmonary hypertension in patients with systemic lupus erythematosus (SLE). While decreased synthesis/ release of prostacyclin ${ }^{2}$ or diminution of its activity ${ }^{3}$ may be responsible for the paradoxical association of the lupus anticoagulant with thrombotic tendencies or states, other mechanisms may be significant. Relative deficiencies of protein C or antithrombin III (ATIII) have been associated with development of a thrombotic diathesis. ${ }^{45}$ Depression of ATIII levels has been noted in SLE, correlating with disease activity. ${ }^{6}$ Perhaps central to the question is the cogent observation by Anderson and $\mathrm{Ali}^{1}$ that warfarin therapy was ineffective in controlling the thrombotic diathesis in their patient, in spite of maintenance of the prothrombin ratio in the therapeutic range. Oral anticoagulants have been generally noted to augment levels of both protein $\mathrm{C}^{7}$ and ATIII. ${ }^{8}$ One exception has been noted. A subgroup of individuals was identified, by Penner and Hunter, ${ }^{9}$ in whom recurrent thrombotic phenomena were noted, even when the prothrombin time was prolonged to the normally 'acceptable' range. That group was categorised by failure of the anticoagulant to produce the expected increase in antithrombin III concentration. As ATIII deficiency-associated phenomena are responsive to ATIII transfusion, ${ }^{10}$ identification of deficiency states would appear to be of more than academic interest. It would be of interest to study plasma ${ }^{8}$ from such patients as described by Anderson and Ali further, to determine if such potentially treatable phenomena were present.

Rheumatology Division,

B M ROTHSCHILD

Menorah Medical Center, and

Kansas University School of Medicine,

USA.

\section{References}

1 Anderson N E, Ali M R. The lupus anticoagulant, pulmonary thromboembolism, and fetal pulmonary hypertension. Ann Rheum Dis 1984; 43: 760-3.

2 Carreras L O. Defreyn G, Machin S J, et al. Arterial thrombosis, intrauterine death and 'lupus' anticoagulant: detection of immunoglobulin interfering with prostacyclin formation. Lancet 1981; i: 244-6.

3 McVerry B A. Machin S J, Parry H, Goldstone A H. Reduced prostacyclin activity in systemic lupus erythematosus. $A n n$ Rheum Dis 1980; 39: 524-5.

4 Rothschild B M. The role of antithrombin III in clinical management of pulmonary embolism. Am J Med 1983; 74: 529-31.

5 Sills R H, Marlar R A, Montgomery R R, et al. Severe homozygous protein $C$ deficiency. J Pediatr 1984: 105: 409-13.

6 Rothschild B M, Jones J V. Chesney C M. et al. Serine esterase inhibitors as predictors of renal disease in systemic lupus erythematosus. Clin Res 1983; 31: 454A.

7 Branson H E, Katz J, Marble R. Griffin J H. Inherited protein $\mathrm{C}$ deficiency and coumarin-responsive chronic relapsing purpura fulminans in a newborn infant. Lancet 1983; ii: 1165-7.

8 Rothschild B M. Serine esterase inhibitors and immune modulation. Semin Arthritis Rheum 1984; 13: 274-92.

9 Penner J A, Hunter M J. Antithrombins: clinical aspects. chemical and biologic properties. In: Jamieson G A, Greenwalt $\mathrm{T} \mathrm{J}$, eds. Trace components of plasma: isolation and clinical significance. New York: Alan R Liss, 1976: 277-300.

10 Blatt P M, White G G II, Goldsmith J C, et al. Antithrombin III transfusion in disseminated intravascular coagulation. Lancet 1978; i: 1212 .

\section{Bufexamac crystals in synovial fluid analysis}

SIR, Bufexamac, a non-steroidal drug for intra-articular injection, was recently introduced. Its pharmacology and efficacy have been studied by several authors. ${ }^{1-4}$ On 
microscopic examination some batches appear as squares or rectangles with rounded angles, but some appear as sticks with sharp or square ends measuring between 3 and $12 \mu \mathrm{m}$. On compensated polarised microscopy they are negatively birefringent and must not be confused with monosodium urate crystals.

Our purpose was to determine what chances there are of encountering such crystals in synovial fluid after an intra-articular injection. We also compared the result of a bufexamac injection with the result of a corticosteroid intra-articular injection.

We selected 94 patients (59 females and 35 males) with chronic exudative gonarthrosis, who had a normal blood analysis and no crystals whatsoever in their synovial fluid.

Forty patients received an intra-articular (IA) injection of $7 \mathrm{mg}$ betamethasone acetate, 36 received an IA injection of $20 \mathrm{mg}$ triamcinolone hexacetonide, and 18 patients received $20 \mathrm{mg}$ bufexamac. All were asked to return after two days. If at that time there was at least $5 \mathrm{ml}$ synovial fluid effusion. a new synovial fluid analysis was performed; if not, we asked the patients to return after five additional days for this analysis.

From the 40 patients who had received IA betamethasone acetate 35 came back for follow up: 14 synovial analyses were performed after two days and in three of them we found betamethasone crystals. Twenty one patients were seen after seven days, and no crystals were found in their synovial fluid.

From the 36 patients who had received IA triamcinolone hexacetonide 31 returned: 11 fluids were aspirated after two days and triamcinolone crystals were found in two. In the synovial fluid of the 20 patients who were seen afteren one week no crystals were found.

In the last group 17 of 18 patients who had received bufexamac were seen in follow up: nine fluids werco aspirated after two days and bufexamac crystals were्ठ found in two; eight patients were seen after seven days $\overline{\bar{\omega}}$. and no crystals were found.

All crystals were extracellular. We conclude that if $\stackrel{\mathbb{Q}}{\Omega}$ synovial fluid examination is performed two days after an intra-articular injection, there is about one chance in fiveof encountering crystals if a crystal suspension drug had been previously injected. After seven days there is not one chance in 50 of finding such crystals.

Centre Médico-Social de Bruxelles.

69 rue des Chartreux.

B-1000 Brussels, Belgium

\section{References}

1 Mardjuadi A. Dequeker J. Double-blind trial comparin bufexamac infiltrations with triamcinolone acetonide infiltra ${ }^{\prime}$ tions in patients with periarthritis of the shoulder. Curr Mecb Res Opin 1978: 5: 401-6.

2 Wauters M. Clinical studies with bufexamac, a non-steroict anti-inflammatory drug. by intra- or periarticular administraz tion. Curr Ther Res 1978: 6: 685-94.

3 Dieux F. Famaey J P. Etude comparative, en double insu. du bufexamac et de lacetonide de triamcinolone en injectiors locale dans le rhumatisme abarticulaire et les arthroses. Acter Rheumatol Scand 1979; 3: 260-4

4 Commandré F A. Gaudebert G. Sacrens E J. Cool J P. Etudio contrôlée en double aveugle comparant le bufexamac et lis bétaméthasone dans les traumatismes dorigine sportive e? l'arthrose. Méd Sport 1983: 5: 60, 316-20.

\section{Book review}

Textbook of Orthopaedic Medicine. Vol. 2. Treatment by Manipulation, Massage and Injection. By $\mathrm{J}$ Cyriax and M Coldham. Pp. 266. £14.50. Bailliere Tindall: London. 1984.

For those familiar with previous editions of this book of practical procedures, there is little new. If you are new to it, and feeling a bit therapeutically nihilistic, try it for a tonic! The dogmatic. optimistic style encourages you to do something positive. One quarter of the procedures are injections: this aspect can be compared with Allan Dixon and Graber's Eular Monograph Local Injection Therapy i Rheumatic Diseases. Cyriax gives better detail on shoulde음 and back injections, while Dixon covers finger and toe joint injections well because of more emphasis on rheumaz toid arthritis. In both, exact details of positioning and injection technique are given. Dixon's line drawings and $x$-rays are an added help; in this book, even a recen? photograph of Mrs Cyriax is reproduced somewhat indis 3 tinctly by the publisher. With controlled trials now showing efficacy of manipulation, the half of the book exactlo describing spinal and peripheral joint manipulation is useful reference for those who have been physically taugh? the rudiments of the art

\section{Note}

\section{Volvo awards for low back pain research}

To encourage research in low back pain the Volvo Company of Göteborg. Sweden, has sponsored three prizes of US $\$ 6000$ each. Awards will be made competitively on the basis of scientific merit in the following three areas: (1) clinical studies; (2) bioengineering studies; (3) studies in other basic science areas. Papers submitted for the contest must contain original material, not previously published or submitted for publication. Multiple author $N$ ship is acceptable. The manuscripts should be in the form of a complete report, not exceeding 30 typewritten pages, $\omega$ double-spaced, and in a form suitable for submission to aर scientific journal. Five copies of each paper submitted ine full should reach the address given below not later than $2 \frac{}{\Phi}$ January 1986. One of the authors should be prepared, an his own expense, to come to Dallas, Texas, USA, at the time of the meeting of the International Society for theo Study of the Lumbar Spine, 4-8 June 1986, to present the paper and to receive the award. Further details from Professor Alf L. Nachemson, Department of Orthopaedice Surgery I, Sahlgren Hospital, S-413 45 Göteborg, Sweden 